\title{
Influence of intrapulpal pressure simulation on the bond strength of adhesive systems to dentin
}

\section{Marcio Vivan Cardoso(a) Simone Gonçalves Moretto(b) Rubens Côrte Real de Carvalho(c) Eliza Maria Agueda Russo(c)}

(a) PhD Student; (b)MSc Student; (c) Associate Professors - Department of Restorative Dentistry, School of Dentistry, University of São Paulo.

\section{Corresponding author:}

Marcio Vivan Cardoso

Departamento de Dentística Restauradora

Faculdade de Odontologia

Universidade de São Paulo

Av. Prof Lineu Prestes, 2227

CEP: 05508-000

E-mail:vivan@usp.br

\begin{abstract}
The purpose of this study was to evaluate the influence of intrapulpal pressure simulation on the bonding effectiveness of etch $\&$ rinse and self-etch adhesives to dentin. Eighty sound human molars were distributed into eight groups, according to the permeability level of each sample, measured by an apparatus to assess hydraulic conductance (Lp). Thus, a similar mean permeability was achieved in each group. Three etch \& rinse adhesives (Prime \& Bond NT - PB, Single Bond -SB, and Excite - EX) and one self-etch system (Clearfil SE Bond - SE) were employed, varying the presence or absence of an intrapulpal pressure (IPP) simulation of $15 \mathrm{cmH}_{2} \mathrm{O}$. After adhesive and restorative procedures were carried out, the samples were stored in distilled water for 24 hours at $37^{\circ} \mathrm{C}$, and taken for tensile bond strength (TBS) testing. Fracture analysis was performed using a light microscope at $40 \mathrm{X}$ magnification. The data, obtained in MPa, were then submitted to the Kruskal-Wallis test $(\alpha=0.05)$. The results revealed that the TBS of SB and EX was significantly reduced under IPP simulation, differing from the TBS of PB and SE. Moreover, SE obtained the highest bond strength values in the presence of IPP. It could be concluded that IPP simulation can influence the bond strength of certain adhesive systems to dentin and should be considered when in vitro studies are conducted.
\end{abstract}

Descriptors: Adhesives; Dentin permeability; Dental bonding; Smear layer. 


\section{Introduction}

It has been widely spread that the demineralized dentin surface must be kept ideally moist during adhesive procedures in order to promote proper resin monomer infiltration into the exposed collagen fibrils. ${ }^{1}$ Actually, a certain amount of water is crucial to prevent the collagen network from collapsing, ${ }^{2}$ while an excessive moisture condition may contribute negatively towards effective bonding to dentin. ${ }^{3}$ However, achieving a "window of opportunity" between overdry and overwet conditions is still a challenge, since not only extrinsic, but also intrinsic sources of humidity must be considered when an adhesive procedure is clinically performed. Considering that intrapulpal pressure (IPP) has hardly been simulated in vitro, the absence of an outward fluid through dentin tubules has represented the most critical difference between clinical and laboratorial conditions. ${ }^{4}$ As a consequence, many authors have discussed the real necessity of employing pulpal pressure simulation when adhesives are tested in vitro, ${ }^{3,5-11}$ although no common sense has been achieved so far. Supposing that adhesives may be differently influenced by perfusion through dentin due to their distinct composition and approach, the purpose of this study was to evaluate whether IPP simulation interferes with the tensile bond strength of different etch $\&$ rinse systems applied on dentin, and how a self-etching system behaves under this condition.

\section{Material and Methods}

Eighty sound human molars from 19-26 yearold patients were stored in distilled water at $4{ }^{\circ} \mathrm{C}$ for a maximum period of 6 months before being used. The teeth were individually embedded in cold-cure acrylic resin (Redelease Ltda., São Paulo, SP, Brazil) and transversally cut in two steps using a slowspeed diamond saw (Labcut 1010 Extec, Enfield, CT, USA) under a copious water supply. The first cutting removed the occlusal enamel, while the subsequent parallel section removed the root portion and exposed the pulp chamber, from which the pulp tissue was carefully removed. Then, the occlusal surface was ground with a 600 grit abrasive paper in an Ecomet 3 polisher (Buehler Ltd., Lake Bluff,
IL, USA) to achieve a standardized remaining dentin thickness of about $1 \mathrm{~mm}$ from the occlusal surface to the roof of the pulp chamber.

In order to determine the permeability (hydraulic conductance) of the specimens, each tooth segment was attached to a metal chamber that was connected to a $364 \mathrm{~cm}$ high water column by means of a silicone tube. All the hydraulic system was filled with distilled water. While the fluid flowed through dentin tubules, the hydraulic conductance of each specimen was measured for 20 minutes by monitoring the movement of a tiny air bubble through a micropipette, which was positioned between the water column and the metal chamber. The hydraulic conductance $\left(\mu \mathrm{l} \mathrm{cm} \mathrm{cmin}^{-1} \mathrm{~cm} \mathrm{H}_{2} \mathrm{O}^{-1}\right)$ of dentin was determined as a function of filtration rate $(\mu \mathrm{l}$ $\min ^{-1}$ ), hydrostatic pressure difference across dentin $\left(\mathrm{cmH}_{2} \mathrm{O}\right)$, and surface area $\left(\mathrm{cm}^{2}\right)$, which was measured with autoCAD Release 14 software (Autodesk, San Rafael, CA, USA). The calculation was used to classify samples according to their permeability levels and the following averages were found: (1) low ( $\mathrm{n}=16$ ), $17.1 \times 10^{-3} \mu \mathrm{l} \mathrm{cm}^{-2} \mathrm{~min}^{-1} \mathrm{cmH}_{2} \mathrm{O}^{-1}$; (2) moderately low $(\mathrm{n}=24), 35.4 \times 10^{-3} \mu \mathrm{cm}^{-2} \mathrm{~min}^{-1}$ $\mathrm{cmH}_{2} \mathrm{O}^{-1}$; (3) moderately high $(\mathrm{n}=24), 54.2 \times 10^{-3}$ $\mu \mathrm{cm}^{-2} \mathrm{~min}^{-1} \mathrm{cmH}_{2} \mathrm{O}^{-1}$; and (4) high ( $\left.\mathrm{n}=16\right), 115.0$ $\times 10^{-3} \mu \mathrm{cm}^{-2} \mathrm{~min}^{-1} \mathrm{cmH}_{2} \mathrm{O}^{-1}$. Later on, the samples were distributed by stratified assignment into 8 groups in accordance with their permeability levels, so that a similar mean permeability was achieved in each group. The groups were then determined by varying the adhesive system, and the presence or absence of intrapulpal pressure (IPP) simulation.

Three etch $\&$ rinse adhesives (Prime \& Bond NT, PB, Single Bond, SB, and Excite, EX) and one self-etch adhesive (Clearfil SE Bond, SE) were selected for this study. The bonding procedures were performed according to the manufacturers' instructions (Table 1).

In order to provide IPP simulation during the adhesive procedures, the water column of the hydraulic system was adjusted to $15 \mathrm{~cm}$ above the sample level, providing a pressure of $15 \mathrm{cmH}_{2} \mathrm{O}$. No pressure was induced for the control groups, in which the water column was set at the sample level $(0 \mathrm{~cm})$. At this moment, physiologic saline solution (LBS, 
São Paulo, SP, Brazil) was used to fill the hydraulic system. After the adhesive procedures were carried out, Filtek Z250 composite (3M Co., St. Paul, MN, USA) was incrementally applied on dentin with the auxiliary use of a cone-shaped bipartite Teflon matrix, with $3 \mathrm{~mm}$ in diameter and $4 \mathrm{~mm}$ in height. Each increment was light-cured for 30 seconds using an XL 1500 light-curing unit (3M Co., St. Paul, $\mathrm{MN}$, USA) with a light output of $500 \mathrm{~mW} / \mathrm{cm}^{2}$. All specimens were then stored in distilled water at $37^{\circ} \mathrm{C}$ for 24 hours before tensile bond strength (TBS) testing, which was performed in an Instron Universal Testing Machine 4442 (Instron Corp., Canton, MA, EUA), at a speed of $0.5 \mathrm{~mm} / \mathrm{min}$. The failure mode was determined at $40 \mathrm{X}$ magnification using a light microscope (Olympus Corp., Tokyo, Japan) and recorded as adhesive (interfacial failure), cohesive in composite, and mixed failure. KruskalWallis analysis and multiple comparisons test were used to determine statistical differences in TBS at a significance level of $5 \%$.
Fourteen additional third molars presenting moderately high dentin permeability were prepared as described before, and then processed for micromorphological analysis of the adhesive interfaces obtained in each condition. The samples were processed as described by Perdigão et al. ${ }^{12}$ (1995), and evaluated by means of scanning electron microscopy (Jeol JXA-6400, Tokyo, Japan).

\section{Results}

The mean bond strengths and standard deviations are presented in Table 2.

All the adhesives presented lower TBS when applied under IPP simulation, although no statistically significant difference was observed for SE and PB. Irrespective of IPP simulation, Clearfil SE Bond showed the highest TBS values, while SB and $\mathrm{PB}$ presented no statistically significant difference when compared to each other $(\mathrm{p}>0.05)$. Finally, EX achieved the lowest bond strength values, although no statistically significant difference was

Table 1 - Adhesive systems: chemical composition and application mode.

\begin{tabular}{|c|c|c|}
\hline Adhesive (manufacturer) & Composition (batch number) & Application \\
\hline $\begin{array}{l}\text { Prime \& Bond NT (Dentsply/ } \\
\text { Caulk, Milford, DE, USA) }\end{array}$ & $\begin{array}{l}\text { Penta, UDMA, resin di- and trimethacrylate, } \\
\text { cethylamine/ethylamine hydrofluoride, nanofillers, } \\
\text { photoinitiators, stabilizer and acetone (109000678) }\end{array}$ & $\begin{array}{l}\text { Apply phosphoric acid } 37 \% \text { for } 15 \mathrm{~s} \text {; rinse for } 15 \mathrm{~s} \text {; } \\
\text { gently air dry; apply ample amounts of adhesive } \\
\text { and leave it undisturbed for } 20 \mathrm{~s} \text {; gently air dry; } \\
\text { photopolymerize for } 10 \mathrm{~s} \text {. }\end{array}$ \\
\hline $\begin{array}{l}\text { Single Bond } \\
\text { ( } 3 M \text { ESPE, St. Paul, MN, USA) }\end{array}$ & $\begin{array}{l}\text { Bis-GMA, HEMA, dimethacrylates, polyalkenoic acid } \\
\text { copolymer, initiators, water and ethanol (2GK) }\end{array}$ & $\begin{array}{l}\text { Apply phosphoric acid } 37 \% \text { for } 15 \mathrm{~s} \text {; rinse for } 15 \mathrm{~s} \text {; } \\
\text { gently air dry; apply } 2 \text { layers of adhesive; gently air- } \\
\text { dry; photopolymerize for } 10 \mathrm{~s} \text {. }\end{array}$ \\
\hline $\begin{array}{l}\text { Excite } \\
\text { (IvoclarNivadent, Amherst, } \\
\text { NY, USA) }\end{array}$ & $\begin{array}{l}\text { HEMA, phosphoric acid acrylate, Bis-GMA, } \\
\text { dimethacrylate, highly dispersed silica, catalysts, } \\
\text { stabilizers, ethanol (D09387) }\end{array}$ & $\begin{array}{l}\text { Apply phosphoric acid } 37 \% \text { for } 15 \mathrm{~s} \text {; rinse for } 15 \mathrm{~s} \text {; } \\
\text { gently air dry; apply ample amounts of adhesive } \\
\text { and scrub the surface for } 10 \mathrm{~s} \text {; gently air-dry; } \\
\text { photopolymerize for } 10 \mathrm{~s} \text {. }\end{array}$ \\
\hline $\begin{array}{l}\text { Clearfil SE Bond } \\
\text { (Kuraray, Osaka, Japan) }\end{array}$ & $\begin{array}{l}\text { Primer: 10-MDP, HEMA, hydrophilic dimethacrylate, } \\
\text { photoinitiator and water (00185A) } \\
\text { Bond: 10-MDP, Bis-GMA, HEMA, hydrophilic } \\
\text { dimethacrylate and microfiller (00176A) }\end{array}$ & $\begin{array}{l}\text { Apply primer and leave it undisturbed for } 20 \mathrm{~s} \text {; } \\
\text { dry with mild air flow, apply bond; gently air flow; } \\
\text { photopolymerize for } 10 \mathrm{~s} \text {. }\end{array}$ \\
\hline
\end{tabular}

Bis-GMA: bisphenol-glycidyl methacrylate; HEMA: hidroxyethilmethacrylate; 10-MDP: 10-methacryloyloxydecyl dihydrogen phosphate; Penta: dipentaerythritole-pentacrylate-phosphoric acid ester; UDMA: urethane dimethacrylate.

Table 2 - Mean bond strength to dentin (MPa \pm standard deviation).

\begin{tabular}{l|c|c|c|c}
\hline \multirow{2}{*}{ Pulpal Pressure } & \multicolumn{4}{|c}{ Adhesive Systems } \\
\cline { 2 - 5 } & Clearfil SE & Prime\&Bond NT & Single Bond & Excite \\
\hline Absent & $20.2 \pm 7.1^{\mathrm{A}}$ & $13.6 \pm 4.9^{\mathrm{BC}}$ & $13.7 \pm 1.9^{\mathrm{B}}$ & $10.9 \pm 3.6^{\mathrm{CD}}$ \\
\hline Present & $15.7 \pm 5.9^{\mathrm{A}, \mathrm{B}}$ & $10.7 \pm 1.6^{\mathrm{CD}}$ & $9.9 \pm 1.5^{\mathrm{DE}}$ & $7.9 \pm 2.1^{\mathrm{E}}$ \\
\hline
\end{tabular}

Means marked with the same superscript letter are not significantly different $(p>0.05)$. 
observed between EX and PB and between EX and SB in the absence and presence of IPP, respectively. The distribution of fracture patterns is graphically presented in Graph 1. Irrespective of the adhesive

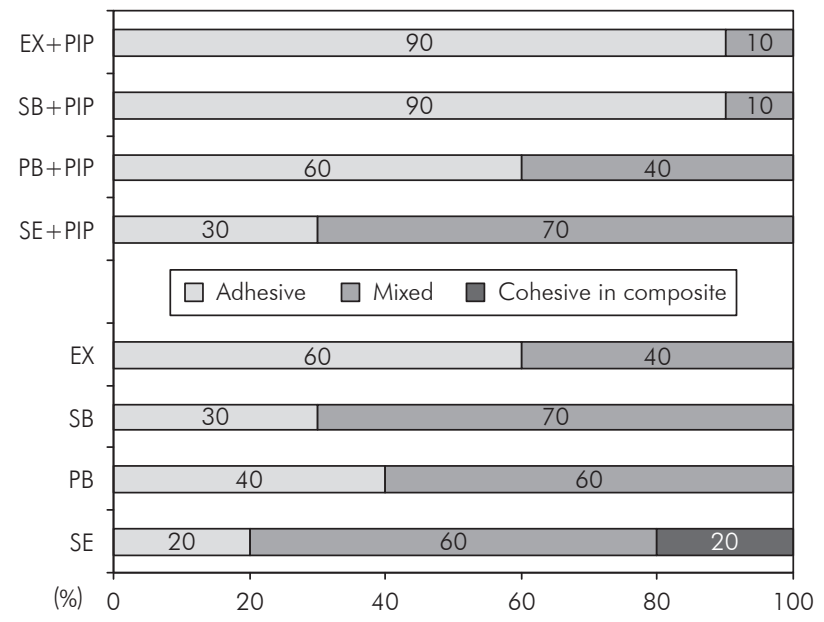

Graph 1 - Graphic presentation of the fracture mode incidence. employed in each group, a higher number of adhesive failures was observed in the presence of IPP simulation.

Resin tag formation was clearly observed for all the adhesive systems used in this study, irrespective of the presence or absence of IPP simulation. This structure, however, was more evident when the adhesive procedure was performed in the absence of fluid flow through dentin (Figure 1).

\section{Discussion}

Although it has been indicated that moisture on the dentin surface is essential for a successful bonding protocol, ${ }^{13}$ an overwet condition may contribute negatively to the adhesive procedure. ${ }^{14}$ The advantages of a wet bonding technique are related to the ability of water to keep the demineralized collagen network open during primer infiltration. Fluid flow through dentin may, however, result in large amounts of water on the surface to be bonded,
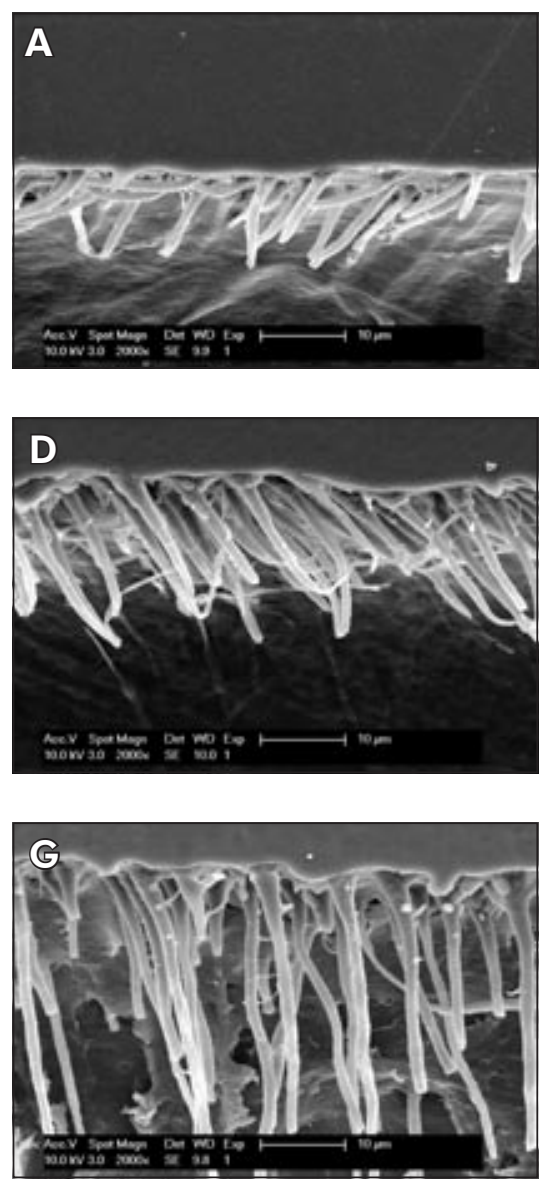
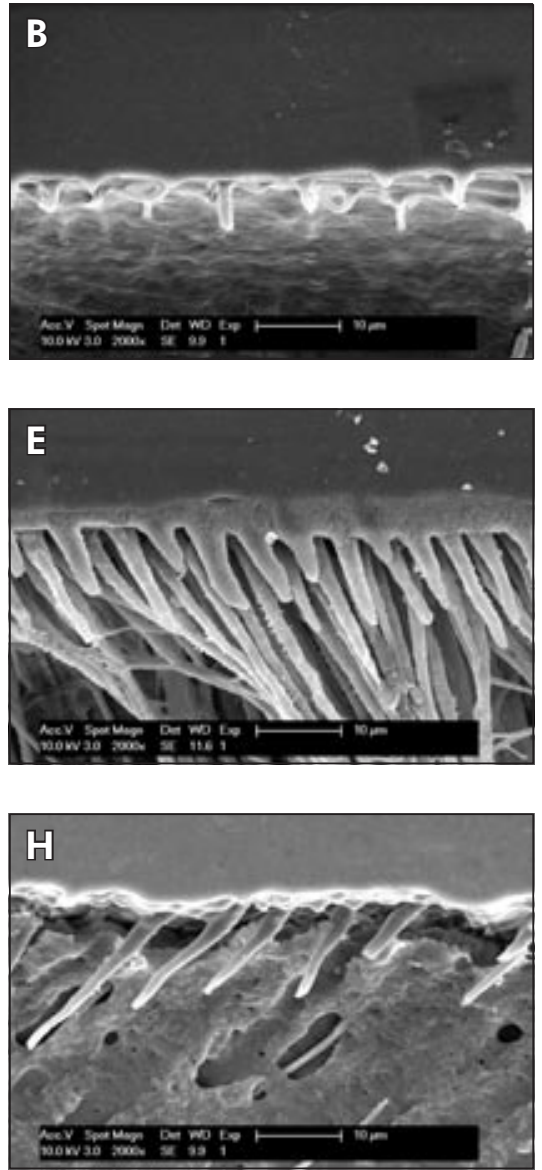
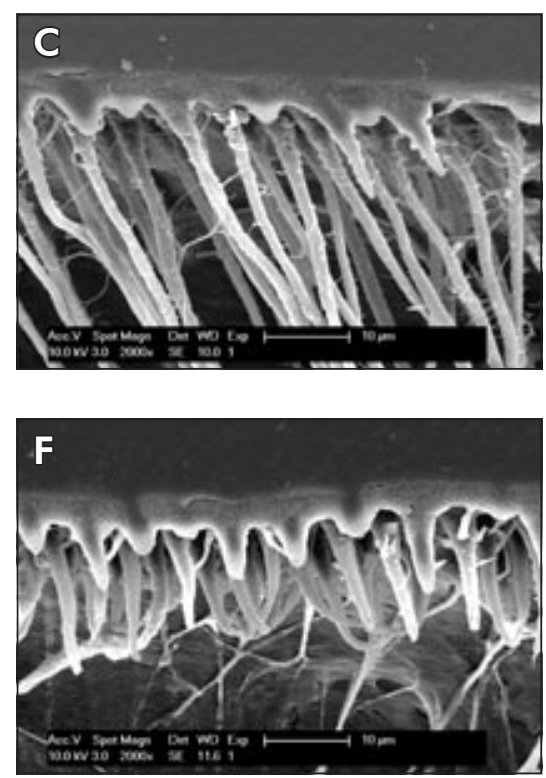

Figure 1 - Adhesive interface of Clearfil SE Bond (A, B), Prime \& Bond NT (C, $\mathbf{D})$, Single Bond (E, F), and Excite (G, $\mathbf{H})$ applied on dentin in the absence $(\mathbf{A}$, $\mathbf{C}, \mathbf{E}, \mathbf{G})$ or presence $(\mathbf{B}, \mathbf{D}, \mathbf{F}, \mathbf{H})$ of IPP. Observe that resin tags are longer and more evident when the adhesives are applied in the absence of intrapulpal pressure simulation $(2,000 \mathrm{X})$. 
thus hampering the optimal interaction between the adhesive and the dentin substrate. ${ }^{7,9,10}$ Perfusion through dentin physically prevents resin monomers from infiltrating the dentinal tubules and demineralized collagen network, thus preventing resin tag and hybrid layer formation. ${ }^{8}$ This statement is in agreement with our findings, since a less evident resin tag formation was observed in the presence of IPP simulation (Figure 1). Furthermore, large amounts of water on the dentin surface result in dilution of the primer components, and a consequent reduction in its ability to displace water from the dentin surface. ${ }^{15}$ Excessive moisture on the adherent substrate is also responsible for a lower degree of resin monomer conversion, reducing the mechanical properties of the adhesive layer. ${ }^{16}$ Based on these hypotheses, many authors have studied the influence of IPP on the bonding effectiveness of adhesives to dentin by simulating pressures ranging from 30 to $37 \mathrm{cmH}_{2} \mathrm{O}^{5,6,8,9}$ Nevertheless, a lower IPP was employed in the present study since the IPP in a hyperemic pulp is not as high as previously established. Some in vivo studies have stated that values of approximately $15 \mathrm{cmH}_{2} \mathrm{O}$ should be used to simulate a hyperemic pulp condition. ${ }^{17,18}$

Clearfil SE Bond presented the highest bond strength values when compared with the other adhesive systems used in this study, irrespective of the presence or absence of IPP simulation. The bonding effectiveness of self-etch adhesives has been widely reported, ${ }^{19,20}$ and has been attributed to their ability to demineralize and infiltrate the dentin surface simultaneously to the same depth, preventing incomplete penetration of the adhesive into the exposed collagen network. ${ }^{20,21}$ Moreover, the presence of smear-layer and smear-plugs during the bonding procedure prevents fluid movement through dentin, acting as an important barrier to dentin permeability. ${ }^{21}$ Therefore, the smear debris may be able to minimize the effects of perfusion through dentin on the bonding effectiveness of self-etch adhesives, and this explains why Clearfil SE Bond was not influenced by IPP simulation in this study.

Despite its etch $\&$ rinse approach, the bonding effectiveness of Prime\&Bond NT was not influenced by perfusion through dentin, even considering the possible occurrence of an overwet phenomenon, and the consequent phase separation of the more hydrophobic components in the adhesive resin. ${ }^{14,16}$ Taking into account that a pressure of $15 \mathrm{cmH}_{2} \mathrm{O}$ was used in this study, the amount of water on dentin surface was probably not large enough to significantly compromise the bond strength of the acetone-based adhesive Prime\&Bond NT. The water-chasing ability of its volatile resin solvent seems to have displaced water effectively from the dentin surface, resulting in an optimal resin infiltration into the collagen network, even in the presence of perfusion through dentin. On the other hand, while acetone presents a higher capacity to displace moisture from the dentin surface by promoting intense water evaporation, alcohol and water are less effective for that purpose. ${ }^{8,22}$ This evidence can explain the negative influence of IPP simulation on the bond strength of Single Bond and Excite, both alcohol-based adhesives, and the increased number of adhesive failures observed in these circumstances, suggesting the development of a weakened interaction between these adhesives and the perfused dentin.

In an attempt to standardize the dentin substrates used in this study, only freshly-extracted, sound, young third molars were employed, and the remaining dentin thickness of each specimen was also controlled. However, variability in dentin permeability among different teeth was clearly detected after the hydraulic conductance measurements. Since variations in dentin permeability can strongly affect the bonding effectiveness of adhesives, ${ }^{15}$ it was crucial not to separate the specimens into the experimental groups at random, but to take care that all of these groups had similar mean dentin permeability. Therefore, variability in dentin permeability was not a limitation for this study at all, since the samples were distributed in accordance with their previously established hydraulic conductance.

Finally, by investigating the effects of IPP simulation, it was endeavored to achieve in vitro research situations closer to real clinical conditions. Considering the limitations of every laboratorial study, however, the results shown and discussed here are but a prediction of the clinical performance of some of the currently available bonding systems. 


\section{Conclusions}

It could be concluded that IPP simulation may interfere with the bond strength of certain adhesive systems to dentin, depending on their composition and approach. Conversely to self-etch and acetonebased etch $\&$ rinse adhesives, alcohol-based adhe-

\section{References}

1. Van Meerbeek B, Yoshida Y, Lambrechts P, Vanherle G, Duke ES, Eick JD et al. A TEM study of two water-based adhesive systems bonded to dry and wet dentin. J Dent Res. 1998;77(1):50-9.

2. Pashley DH, Ciucchi B, Sano H, Horner JA. Permeability of dentin to adhesive agents. Quintessence Int. 1993;24(9):61831.

3. Ozok AR, Wu MK, De Gee AJ, Wesselink PR. Effect of dentin perfusion on the sealing ability and microtensile bond strengths of a total-etch versus an all-in-one adhesive. Dent Mater. 2004;20(5):479-86.

4. Pashley DH. In vitro simulations of in vivo bonding conditions. Am J Dent. 1991;4(5):237-40.

5. Elhabashy A, Swift EJ Jr., Boyer DB, Denehy GE. Effects of dentin permeability and hydration on the bond strengths of dentin bonding systems. Am J Dent. 1993;6(3):123-6.

6. Gernhardt CR, Schaller HG, Kielbassa AM. The influence of human plasma used for dentin perfusion on tensile bond strength of different light-curing materials. Am J Dent. 2005;18(5):318-22.

7. Hosaka K, Nakajima M, Yamauti M, Aksornmuang J, Ikeda M, Foxton RM et al. Effect of simulated pulpal pressure on all-in-one adhesive bond strengths to dentin. J Dent. 2007;35(3):207-13.

8. Moll K, Haller B. Effect of intrinsic and extrinsic moisture on bond strength to dentin. J Oral Rehabil. 2000;27(2):15065.

9. Moll K, Park H, Haller B. Effect of simulated pulpal pressure on dentin bond strength of self-etching bonding systems. Am J Dent. 2005;18(5):335-9.

10. Sauro S, Pashley DH, Montanari M, Chersoni S, Carvalho RM, Toledano M et al. Effect of simulated pulpal pressure on dentin permeability and adhesion of self etch adhesives. Dent Mater. 2007;23(6):705-13. sives were negatively influenced by the presence of perfusion through dentin in terms of bonding effectiveness. Finally, the IPP simulation should be considered when bond strength methodologies are performed in vitro.

11. Sengun A, Ozturk B, Ozer F. The effect of simulated intrapulpal pressure on bond strength to enamel and dentine. J Oral Rehabil. 2003;30(5):550-5.

12. Perdigão J, Lambrechts P, Van Meerbeek B, Vanherle G, Lopes AL. Field emission SEM comparison of four postfixation drying techniques for human dentin. J Biomed Mater Res. 1995;29(9):1111-20.

13. Kanka J. Resin bonding to wet substrate I. Bonding to dentin. Quintessence Int. 1992;23(1):39-41.

14. Tay FR, Gwinnett JA, Wei SH. Micromorphological spectrum from overdrying to overwetting acid-conditioned dentin in water free, acetone-based, single-bottle primer/adhesives. Dent Mater. 1996;12(4):236-44.

15. Pereira PN, Okuda M, Sano H, Yoshikawa T, Burrow MF, Tagami J. Effect of intrinsic wetness and regional difference on dentin bond strength. Dent Mater. 1999;15(1):46-53.

16. Jacobsen T, Soderholm KJ. Some effects of water on dentin bonding. Dent Mater. 1995;11(2):132-6.

17. Ciucchi B, Bouillaguett S, Holz J, Pashley D. Dentinal fluid dynamics in human teeth, in vivo. J Endod. 1995;21(4):191-4.

18. Vongsavan N, Matthews B. Fluid flow through cat dentine in vivo. Arch Oral Biol. 1992;37(3):175-85.

19. Mandras RS, Thurmond JW, Latta MA, Matranga LF, Kildee JM, Barkmeier WW. Three-year clinical evaluation of the Clearfil Liner Bond system. Oper Dent. 1997;22(6):266-70.

20. Tanumiharja M, Burrow MF, Tyas MJ. Microtensile bond strengths of seven dentin adhesive systems. Dent Mater. 2000;16(3):180-7.

21. Grégoire G, Joniot S, Guignes P, Millas A. Dentin permeability: Self-etching and one-bottle dentin bonding systems. J Prosthet Dent. 2003;90(1):42-9.

22. Lopes GC, Cardoso PC, Vieira LC, Baratieri LN, Rampinelli $\mathrm{K}$, Costa G. Shear bond strength of acetone-based one-bottle adhesive systems. Braz Dent J. 2006;17(1):39-43. 